\title{
Has the Copayment Ceiling Improved Financial Protection in the Korean National Health Insurance System? Evidence From the 2009 Policy Change
}

\author{
Tae-Jin Lee ${ }^{1,2}$, Chelim Cheong ${ }^{2}$ \\ ${ }^{1}$ Department of Public Health Science, Graduate School of Public Health, Seoul National University, Seoul; ${ }^{2}$ Institute of Health and Environment, \\ Graduate School of Public Health, Seoul National University, Seoul, Korea
}

Objectives: To relieve the financial burden faced by households, the Korean National Health Insurance (NHI) system introduced a "copayment ceiling," which evolved into a differential ceiling in 2009, with the copayment ceiling depending on patients' income. This study aimed to examine the effect of the differential copayment ceiling on financial protection and healthcare utilization, particularly focusing on whether its effects varied across different income groups.

Methods: This study obtained data from the Korea Health Panel. The number of households included in the analysis was 6555 in 2008, 5859 in 2009, 5539 in 2010, and 5372 in 2011. To assess the effects of the differential copayment ceiling on utilization, out-of-pocket (OOP) payments, and catastrophic payments, various random-effects models were applied. Utilization was measured as treatment days, while catastrophic payments were defined as OOP payments exceeding $10 \%$ of household income. Among the right-hand side variables were the interaction terms of the new policy with income levels, as well as a set of household characteristics.

Results: The differential copayment ceiling contributed to increased utilization regardless of income levels both in all patients and in cancer patients. However, the new policy did not seem to reduce significantly the incidence of catastrophic payments among cancer patients, and even increased the incidence among all patients.

Conclusions: The limited effect of the differential ceiling can be attributed to a high proportion of direct payments for services not covered by the $\mathrm{NHI}$, as well as the relatively small number of households benefiting from the differential ceilings; these considerations warrant a better policy design.

Key words: Health insurance, Out-of-pocket payments, Health care costs, Copayment ceiling, Financial protection, Korea

Received: September 23, 2017 Accepted: November 9, 2017

Corresponding author: Tae-Jin Lee, PhD

1 Gwanak-ro, Gwanak-gu, Seoul 08826, Korea

Tel: +82-2-880-2726, Fax: +82-2-745-9104

E-mail: tjlee@snu.ac.kr

This is an Open Access article distributed under the terms of the Creative Commons Attribution Non-Commercial License (http://creativecommons.org/licenses/bync/4.0// which permits unrestricted non-commercial use, distribution, and reproduction in any medium, provided the original work is properly cited.

\section{INTRODUCTION}

Many countries are trying to achieve universal health coverage $(\mathrm{UHC})$, which is expected to improve the health of the population through better access to health services and to provide financial protection for households [1]. However, it is often the case that some developing countries trying to achieve UHC do not have enough resources to provide com- 
prehensive benefit coverage, even though they can achieve universal population coverage (UPC). For those countries, an incremental approach to the expansion of benefit coverage (i.e., UPC first, and then a gradual expansion of benefit coverage) is often suggested, and this took place in Korea.

Korea achieved UPC through National Health Insurance (NHI) in 1989, only 12 years after its first social health insurance (SHI) program was introduced. Despite the early achievement of UPC, the Korean NHI has been characterized by having high out-of-pocket (OOP) payments due to limited benefit coverage, which had to do with the low contributions that helped make it possible to achieve UPC in such a short period [2]. The Korean government has made various efforts to relieve households of the financial burden imposed by high OOP payments, such as the "copayment ceiling" introduced in 2004, whereby patients were responsible for paying copayments only up to a pre-designated ceiling of 3 million Korean won (KRW) (about US dollar $1=$ KRW 1000) per 6 months, and were exempt from paying expenditures above that ceiling. Although the uniform ceiling was lowered to KRW 2 million per 6 months in 2007, the criticism was made that since the uniform ceiling was applied to all households regardless of their ability to pay, it was more favorable to the rich who could afford expensive health care and thus whose copayments were more likely to exceed the ceiling. As a result, a differential or tiered ceiling on copayments was introduced in 2009, with the copayment ceiling depending on patients' income. Using data on health insurance contributions as a proxy for ability to pay, the insurer categorized all households into 3 groups: the lower $50 \%$ (group 1), the middle $30 \%$ (group 2), and the upper $20 \%$ (group 3). The new ceilings were KRW 2 million, 3 million, and 4 million per year, respectively. This meant that the ceilings for group 1 and group 2 were lowered by KRW 2 million and 1 million per year, respectively, while that for group 3 remained unchanged.

OOP payments such as copayments and user fees are often used as tools to prevent patients' moral hazard and sometimes as extra sources of health financing where resources are limited. However, it has been reported that OOP payments have the disadvantages of discouraging utilization and being a barrier to seeking health care [3] or imposing a financial burden when health care is inevitably sought [4], which is particularly true of the poor. Thus, reducing the copayment or eliminating user fees is expected to improve access to health services and to provide better financial protection. Although introducing an SHI or achieving UPC has generally reduced the frequency of financial catastrophes in various healthcare settings [5-8], some evidence shows that reducing copayments or eliminating user fees does not necessarily lead to the reduction of catastrophic payments, with the effects of these policies on financial protection varying depending on the health system [9-11].

Likewise, it is uncertain whether the ceiling on copayments, in the Korean context, improved financial protection by reducing OOP payments, even though it may have easily increased the utilization of health services, particularly among people with unmet needs because of high OOP payments. Moreover, it is not clear whether the effects of the differential ceiling vary across different income groups. Furthermore, the impact of the new policy could be different depending on the size of the target population and the nature of OOP payments inherent to Korea.

Thus, the aim of this study was to examine the effect of the differential copayment ceiling on financial protection and utilization, particularly focusing on whether its effects varied across different income groups. We further added to the available evidence on this issue by analyzing both all households with patients and households with cancer patients. This study may contribute to shedding light on finding a path for many developing countries trying to achieve UHC with limited resources.

\section{METHODS}

\section{Data}

The study drew upon data from the Korea Health Panel (KHP) survey, which is conducted annually with a nationally representative sample of households and provides the best available longitudinal data on health utilization and healthcare expenditures in Korea. This study used the data available from 2008 to 2011. The number of households included in the study was 6555 in 2008, 5859 in 2009, 5539 in 2010, and 5372 in 2011, respectively. This study only included households enrolled in the $\mathrm{NHI}$ because the copayment ceiling is inherently linked to the NHI. The summary statistics of households included in the analysis are given in Table 1. In addition, trends in utilization, OOP payments and their share of income, and the incidence of catastrophic payments by income group are shown in Figure 1 and Table 2.

Household income included the wage income of all household members as well as incomes from other sources such as financial assets and real estate. OOP payments are health ex- 
Table 1. Household characteristics by survey round

\begin{tabular}{|c|c|c|c|c|c|c|c|c|c|}
\hline \multirow{2}{*}{ Variables } & & \multicolumn{4}{|c|}{ All households } & \multicolumn{4}{|c|}{ Households with cancer patients } \\
\hline & & $\begin{array}{c}2008 \\
(n=6555)\end{array}$ & $\begin{array}{c}2009 \\
(n=5859)\end{array}$ & $\begin{array}{c}2010 \\
(n=5539)\end{array}$ & $\begin{array}{c}2011 \\
(n=5372)\end{array}$ & $\begin{array}{c}2008 \\
(n=505)\end{array}$ & $\begin{array}{c}2009 \\
(n=487)\end{array}$ & $\begin{array}{c}2010 \\
(n=486)\end{array}$ & $\begin{array}{c}2011 \\
(n=516)\end{array}$ \\
\hline \multirow[t]{2}{*}{ Gender of household head (\%) } & Men & 86.5 & 85.9 & 85.3 & 84.1 & 91.9 & 90.8 & 90.3 & 86.2 \\
\hline & Women & 13.5 & 14.1 & 14.7 & 15.9 & 8.1 & 9.2 & 9.7 & 13.8 \\
\hline \multirow[t]{7}{*}{ Age of household head (\%) } & $20 \mathrm{~s}$ & 2.4 & 1.6 & 1.5 & 1.4 & 1.0 & 0.8 & 0.8 & 0.6 \\
\hline & $30 \mathrm{~s}$ & 19.3 & 16.9 & 16.2 & 13.9 & 10.5 & 9.9 & 8.6 & 6.6 \\
\hline & 40 s & 25.6 & 25.9 & 25.5 & 24.9 & 25.7 & 21.8 & 19.1 & 19.4 \\
\hline & 50 s & 21.3 & 21.4 & 21.1 & 21.3 & 24.2 & 24.9 & 26.1 & 24.8 \\
\hline & $60 \mathrm{~s}$ & 18.5 & 19.4 & 20.0 & 20.0 & 22.0 & 23.0 & 25.5 & 27.1 \\
\hline & $70 \mathrm{~s}$ & 11.4 & 12.6 & 13.6 & 15.7 & 15.4 & 17.7 & 17.7 & 19.0 \\
\hline & $80 \mathrm{~s}$ & 1.5 & 2.2 & 2.1 & 2.9 & 1.2 & 2.1 & 2.1 & 2.5 \\
\hline \multirow{4}{*}{$\begin{array}{l}\text { Employment status of } \\
\text { household head (\%) }\end{array}$} & Regular & 33.9 & 31.5 & 30.9 & 30.0 & 25.5 & 26.7 & 25.5 & 24.0 \\
\hline & Irregular & 15.8 & 16.6 & 18.5 & 17.6 & 12.3 & 12.3 & 14.4 & 14.5 \\
\hline & Self-employed & 25.2 & 32.2 & 29.0 & 29.2 & 28.3 & 35.1 & 30.5 & 30.4 \\
\hline & Unemployed & 25.1 & 19.6 & 21.6 & 23.3 & 33.9 & 25.9 & 29.6 & 31.0 \\
\hline \multicolumn{2}{|l|}{ No. of household members } & $3.16 \pm 1.28$ & $3.13 \pm 1.29$ & $3.10 \pm 1.30$ & $3.05 \pm 1.32$ & $3.25 \pm 1.24$ & $3.16 \pm 1.24$ & $3.16 \pm 1.21$ & $3.11 \pm 1.30$ \\
\hline \multicolumn{2}{|c|}{$\%$ of households with members aged $65+$} & 28.8 & 31.7 & 32.7 & 35.0 & 36.4 & 40.0 & 42.0 & 41.1 \\
\hline \multicolumn{2}{|c|}{ Charlson comorbidity index } & $0.56 \pm 1.00$ & $0.61 \pm 1.04$ & $0.60 \pm 1.04$ & $0.65 \pm 1.08$ & $2.61 \pm 0.99$ & $2.60 \pm 0.97$ & $2.59 \pm 1.00$ & $2.70 \pm 1.08$ \\
\hline \multicolumn{2}{|c|}{ Annual household income (USD) } & $31529 \pm 24334$ & $33023 \pm 25911$ & $35850 \pm 29982$ & $35919 \pm 25700$ & $35077 \pm 30563$ & $35373 \pm 26192$ & $40078 \pm 38034$ & $39212 \pm 28261$ \\
\hline \multicolumn{2}{|c|}{ Annual OOP health expenditures (USD) } & $1074 \pm 2363$ & $1170 \pm 1659$ & $1299 \pm 1839$ & $1408 \pm 2257$ & $2474 \pm 3276$ & $2319 \pm 2688$ & $2585 \pm 2864$ & $2786 \pm 4750$ \\
\hline \multicolumn{2}{|c|}{ 00P payments as share of household income (\%) } & $6.3 \pm 22.5$ & $8.1 \pm 66.9$ & $6.5 \pm 14.7$ & $7.4 \pm 45.2$ & $13.3 \pm 20.9$ & $11.3 \pm 17.6$ & $12.7 \pm 25.2$ & $12.6 \pm 24.3$ \\
\hline
\end{tabular}

Values are presented as \% or mean \pm standard deviation.

OOP, out of pocket; USD, US dollar.
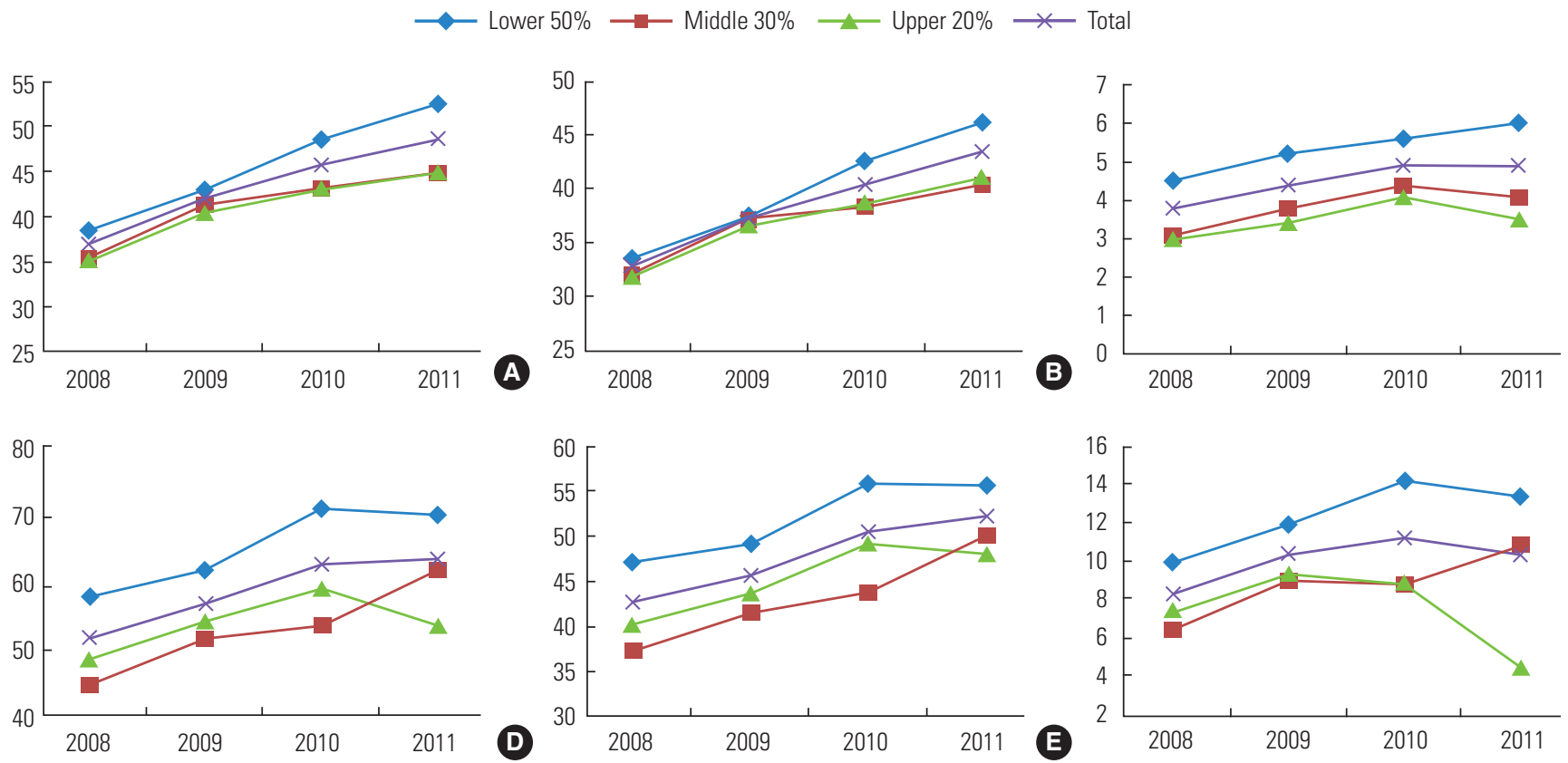

Figure 1. Trends in utilization by income group. (A) All treatment days, (B) outpatient days, (C) inpatient days, (D) all treatment days, (E) outpatient days, and (F) inpatient days. (A)-(C) are for all households and (D)-(F) are for households with cancer patients.

penditures that patients pay at the time of using health services and comprise not only copayment for services covered by the $\mathrm{NHI}$, but also direct payments for services not covered. Treatment days, as a measure of utilization, included outpa- tient and emergency visits, as well as inpatient days. As a measure of financial protection, catastrophic payments were defined as an OOP payment exceeding 10\% of household income [12]. 
Table 2. Trend in OOP and catastrophic payments by income level

\begin{tabular}{|c|c|c|c|c|c|c|c|c|c|}
\hline \multirow{2}{*}{ Variables } & \multirow{2}{*}{ Groups $^{1}$} & \multicolumn{4}{|c|}{ All households } & \multicolumn{4}{|c|}{ Households with cancer patients } \\
\hline & & 2008 & 2009 & 2010 & 2011 & 2008 & 2009 & 2010 & 2011 \\
\hline \multirow[t]{4}{*}{ OOP (USD) } & Group 1 & 989 & 1008 & 1171 & 1325 & 2314 & 2218 & 2631 & 2660 \\
\hline & Group 2 & 1037 & 1200 & 1287 & 1354 & 2333 & 2343 & 2410 & 2554 \\
\hline & Group 3 & 1335 & 1527 & 1623 & 1680 & 2948 & 2487 & 2698 & 3303 \\
\hline & Total & 1075 & 1171 & 1296 & 1411 & 2477 & 2324 & 2583 & 2784 \\
\hline \multirow[t]{4}{*}{ О०P as share of income (\%) } & Group 1 & 10.0 & 13.4 & 10.2 & 11.8 & 21.7 & 18.3 & 22.4 & 20.6 \\
\hline & Group 2 & 3.0 & 3.2 & 3.3 & 3.4 & 6.9 & 6.3 & 6.3 & 6.2 \\
\hline & Group 3 & 2.1 & 2.3 & 2.3 & 2.4 & 4.6 & 3.9 & 3.9 & 4.6 \\
\hline & Total & 6.3 & 8.1 & 6.5 & 7.4 & 13.3 & 11.3 & 12.7 & 12.6 \\
\hline \multirow{4}{*}{$\begin{array}{l}\% \text { of households with catastrophic } \\
\text { payments }\end{array}$} & Group 1 & 23.1 & 24.9 & 26.7 & 28.2 & 52.7 & 51.3 & 54.9 & 51.8 \\
\hline & Group 2 & 5.3 & 6.5 & 5.9 & 6.2 & 16.2 & 19.9 & 15.8 & 16.8 \\
\hline & Group 3 & 2.4 & 3.1 & 3.1 & 2.3 & 9.7 & 11.7 & 6.3 & 3.1 \\
\hline & Total & 13.6 & 15.0 & 15.7 & 16.4 & 31.9 & 32.4 & 30.5 & 30.0 \\
\hline
\end{tabular}

OOP, out-of-pocket; USD, US dollar.

'Groups $1-3$ denote the lower $50 \%$, middle 30\%, and upper 20\%, respectively, based on insurance contributions.

\section{Estimation Strategy}

To assess the effect of the differential copayment ceiling on utilization, OOP payments, and catastrophic payment, we applied different random-effects models depending on the dependent variables. Since utilization was measured as the number of visits or inpatient days, which are count data, randomeffects Poisson models were applied. Taking account of the heavy tail of OOP payments, they were log-transformed before the random-effects regression models were applied. Finally, random-effects logit models were applied to the incidence of a catastrophic payment, which was binary, 0 or 1 .

$$
\begin{gathered}
Y_{i t}=\beta_{0}+\beta_{1} \text { post }+\beta_{2} \text { groups }+\beta_{3} \text { post }{ }^{*} \text { groups }+\beta_{4} d_{2010}+\beta_{5} d_{2011} \\
+\chi_{i t}^{\prime} \gamma+u_{i t}
\end{gathered}
$$

In this equation, $Y_{\text {it }}$ represents the amount of utilization, OOP payment, or the incidence of catastrophic payment of household $i$ at time $t$. The model included a variable indicating the post-intervention (policy) state along with 2 time trends $\left(\mathrm{d}_{2010}, \mathrm{~d}_{2011}\right)$; its interaction terms with different income groups (groups 2 and 3); and a set of household characteristics ( $\left.x_{i t}\right)$. The variables controlled for included demographics (age and gender of household head, household size, and the presence of an elderly member), occupation of the household head, and health status (Charlson comorbidity index [CCl] of household members). The $\mathrm{CCl}$ was constructed by adding the weights given to each of a set of chronic diseases that all household members had [13].

\section{RESULTS}

\section{Trends in Utilization, Out-of-pocket Payments,} and Catastrophic Payments

For all households, the utilization of health services, especially outpatient visits, increased over time among all income groups, and the number of treatment days in 2011 amounted to 48 days per household on average, with some variation between groups (Figure 1(A)-(C)). OOP payments also increased over time across different groups, but group 3 consistently spent more than the other two groups (Table 2). Broadly speaking, the share of income allocated to OOP payments was over $10 \%$ for group 1, while it was as low as 3 and $2 \%$, respectively, for groups 2 and 3 . This led to a stark contrast in catastrophic payments among the different income groups. The incidence of catastrophic payments among group 1 kept increasing, and was as high as $28.2 \%$ in 2011, while the incidence for the other 2 groups remained relatively low and stable (Table 2).

In households with cancer patients, the utilization of health services increased over time, except for a decrease among group 3 in 2011, which had to do with a sharp decrease in inpatient days (Figure 1(D- $(\mathrm{P})$ ). The number of treatment days amounted to 62 days per household, about 30\% more than that of all patients. OOP payments decreased, with differences between groups becoming smaller in 2009, after which they increased very rapidly, with the gap between groups widening. The OOP share of income was over $20 \%$ for group 1 , while it was as low as 6 and 4\%, respectively, for groups 2 and 3. On 
Table 3. Effects of the copayment ceiling on utilization, OOP payments, and catastrophic payments among all households

\begin{tabular}{|c|c|c|c|c|c|c|c|}
\hline \multirow{2}{*}{ Variables } & & \multicolumn{2}{|c|}{ Treatment days } & \multicolumn{2}{|c|}{$\log (00 P)$} & \multicolumn{2}{|c|}{ Catastrophic payments } \\
\hline & & ME & $p$-value & coefficients & $p$-value & ME & $p$-value \\
\hline Gender of household head (ref: women) & & 7.445 & $<0.001$ & 0.329 & $<0.001$ & 0.012 & 0.003 \\
\hline Age of household head & & 0.745 & $<0.001$ & 0.097 & $<0.001$ & 0.012 & $<0.001$ \\
\hline No. of family members & & 5.351 & $<0.001$ & 0.180 & $<0.001$ & -0.006 & $<0.001$ \\
\hline \multirow{3}{*}{$\begin{array}{l}\text { Employment status of household head } \\
\text { (ref: regular) }\end{array}$} & Irregular & -0.758 & 0.001 & -0.161 & $<0.001$ & -0.005 & 0.29 \\
\hline & Self-employed & -0.627 & 0.02 & -0.107 & $<0.001$ & 0.006 & 0.26 \\
\hline & Unemployed & 0.982 & $<0.001$ & -0.022 & 0.49 & 0.031 & $<0.001$ \\
\hline \multirow[t]{2}{*}{ Income (ref: group 1) } & Group 2 & -0.604 & 0.01 & 0.125 & $<0.001$ & -0.058 & $<0.001$ \\
\hline & Group 3 & -0.209 & 0.50 & 0.234 & $<0.001$ & -0.078 & $<0.001$ \\
\hline Charlson comorbidity index & & 4.500 & $<0.001$ & 0.374 & $<0.001$ & 0.032 & $<0.001$ \\
\hline Having an elderly family member (ref: no) & & 12.592 & $<0.001$ & 0.222 & $<0.001$ & 0.031 & $<0.001$ \\
\hline Post & & 4.380 & $<0.001$ & 0.138 & $<0.001$ & 0.005 & 0.18 \\
\hline Post* group 2 & & -0.782 & 0.001 & -0.008 & 0.83 & -0.001 & 0.89 \\
\hline Post* group 3 & & -0.846 & 0.002 & 0.014 & 0.73 & 0.005 & 0.72 \\
\hline Year 2010 & & 3.504 & $<0.001$ & 0.129 & $<0.001$ & 0.003 & 0.46 \\
\hline Year 2011 & & 5.476 & $<0.001$ & 0.149 & $<0.001$ & 0.001 & 0.79 \\
\hline Constant & & & & 2.235 & $<0.001$ & & \\
\hline
\end{tabular}

OOP, out of pocket; ME, marginal effect.

Table 4. Effects of the copayment ceiling on utilization, OOP payments, and catastrophic payments among households with cancer patients

\begin{tabular}{|c|c|c|c|c|c|c|c|}
\hline \multirow{2}{*}{ Variables } & & \multicolumn{2}{|c|}{ Treatment days } & \multicolumn{2}{|c|}{$\log (00 P)$} & \multicolumn{2}{|c|}{ Catastrophic payment } \\
\hline & & ME & $p$-value & Coefficients & $p$-value & ME & $p$-value \\
\hline Gender of household head (ref: women) & & 16.743 & $<0.001$ & 0.143 & 0.11 & 0.044 & 0.23 \\
\hline Age of household head & & 1.438 & 0.03 & 0.071 & 0.01 & 0.027 & 0.06 \\
\hline No. of family members & & 3.008 & $<0.001$ & 0.054 & 0.04 & -0.038 & 0.003 \\
\hline \multirow{3}{*}{$\begin{array}{l}\text { Employment status of household head } \\
\text { (ref: regular) }\end{array}$} & Irregular & -8.377 & $<0.001$ & -0.073 & 0.39 & 0.003 & 0.94 \\
\hline & Self-employed & -5.547 & $<0.001$ & -0.060 & 0.41 & 0.044 & 0.29 \\
\hline & Unemployed & -9.209 & $<0.001$ & -0.066 & 0.41 & 0.066 & 0.15 \\
\hline \multirow[t]{2}{*}{ Income (ref: group 1) } & Group 2 & -0.733 & 0.60 & -0.061 & 0.56 & -0.215 & $<0.001$ \\
\hline & Group 3 & -3.129 & 0.04 & 0.177 & 0.12 & -0.273 & $<0.001$ \\
\hline Charlson comorbidity index & & 4.850 & $<0.001$ & 0.193 & $<0.001$ & 0.056 & $<0.001$ \\
\hline Having an elderly family member (ref: no) & & 30.676 & $<0.001$ & 0.191 & 0.005 & 0.133 & $<0.001$ \\
\hline Post & & 5.453 & $<0.001$ & -0.153 & 0.05 & -0.012 & 0.75 \\
\hline Post* group 2 & & -6.079 & $<0.001$ & 0.154 & 0.19 & 0.035 & 0.59 \\
\hline Post* group 3 & & 2.346 & 0.11 & 0.036 & 0.77 & -0.030 & 0.68 \\
\hline Year 2010 & & 2.127 & $<0.001$ & 0.092 & 0.12 & -0.028 & 0.35 \\
\hline Year 2011 & & 2.080 & 0.001 & 0.083 & 0.16 & -0.057 & 0.04 \\
\hline Constant & & & & 3.841 & $<0.001$ & & \\
\hline
\end{tabular}

OOP, out of pocket; ME, marginal effect.

average, the incidence of catastrophic payments remained stable over the years. However, it reached a remarkably high level (over 50\%) among group 1, while it decreased among group 3 to be as low as 3.1\% in 2011 (Table 2).

\section{Effects of the Differential Copayment Ceiling Utilization}

The random-effects Poisson models showed that for all patients, the copayment ceiling significantly increased utilization among all groups, with an even larger increase among group 1. For cancer patients, the copayment ceiling increased utilization among groups 1 and 3, with a slight decrease among group 2 (Tables 3 and 4).

\section{Out-of-pocket payments}

For all patients, OOP payments for group 1 increased after the new policy by $13.8 \%$, but the effect did not show a significant difference across income groups, which means that the 
copayment ceiling increased OOP payments substantively regardless of income group (Table 3). However, this was not the case for cancer patients, among whom OOP payments decreased significantly in group 1 by $15.3 \%$, while it did not decrease in group 2 and showed a smaller and non-significant decrease in group 3 (Table 4).

\section{Catastrophic payments}

For all patients, the number of households in which OOP payments exceeded $10 \%$ of household income showed a tendency to increase, though not to a significant extent, with little difference across income groups (Table 3). In contrast, the incidence of catastrophic payments seemed to decrease among cancer patients, though not significantly, except for group 2 (Table 4).

\section{DISCUSSION}

The new policy of the differential copayment ceiling aimed to improve financial protection by reducing copayments, particularly for low-income and middle-income households. However, the results showed that the new policy did not seem to reduce significantly the incidence of catastrophic payments among cancer patients, and that it even seemed to increase the incidence among all patients. Looking more closely into the data can help interpret these findings to some extent.

One possibility is that the number of households benefiting from the new copayment ceiling is still limited. The proportion of those households of which the copayment was above the old ceiling (KRW 4 million per year)-in other words, those that were benefiting from the uniform ceiling - was as low as $1.7 \%$ for all patients and $1.4 \%$ for cancer patients, respectively. The differential ceiling added new beneficiaries to them, so that the proportion of beneficiaries increased by $2.8 \%$ of all patients and $2.4 \%$ of cancer patients, which left the vast majority of the households, 95.5 and $96.2 \%$, respectively, still not benefiting from the copayment ceiling.

Overall, the differential ceiling increased utilization regardless of income levels, which was true for all patients and cancer patients. However, further examination of the data reveals different stories about changes in OOP between the 2 types of patients. Among all patients, for example, those households spending less than the new ceiling (KRW 2 or 3 million) did not still reach the ceiling in spite of increased use and thus paid a higher OOP, which led to an increased likelihood of cat- astrophic payments. As for those households spending more than the old ceiling (KRW 4 million), their extra benefit (i.e., reduction in the copayment by KRW 2 or 1 million) was most likely to reduce their OOP. However, the reduction was not enough to lower the incidence of catastrophic payments. This is because of the high proportion of direct payments for services not covered by the NHI. Considering the high proportion of households not benefiting from the new ceiling, it turned out that overall OOP payments increased and catastrophic payments also showed an increasing trend for all patients.

In contrast, for cancer patients, whose average OOP payments were more than twice those of all patients, the increase in utilization did not lead to increases in OOP payments. Instead, along with many existing protective measures for reducing copayments for cancer patients, the lowered ceiling contributed to a further reduction in copayments and overall OOP payments (Table 2). Nevertheless, the reductions in the copayments did not reduce the frequency of catastrophic payments among cancer patients. Again, this was because the proportion of direct payments for non-covered services that most cancer patients used was remarkably high. In fact, the direct payments of cancer patients were about 4 times as high as those of all patients, although the copayments were comparable between them.

The new policy of a differential ceiling on copayments, introduced to alleviate the financial burden caused by the utilization of health services in the $\mathrm{NHI}$, has some implications for equity. Compared to the uniform ceiling, the differential ceiling increased the number of households that benefited from the ceiling among group 1 and group 2, although to a lesser extent, while it brought no change for group 3. For all patients, for example, the proportion of those benefiting from the differential ceiling increased from 1.5 to $6.2 \%$ in group 1 and from 1.3 to $2.9 \%$ in group 2. Similar improvements were observed among cancer patients. Further, it led to increased utilization among all groups, with even greater increase among group 1.

Unlike its positive effect on utilization, the effect of the differential copayment ceiling on financial protection seemed to be limited, which has 2 policy implications. First, based on the distribution of copayments, the percentage of the households that would benefit from the new policy remained very low, despite a slight increase. This is because the ceiling was not well 'differentiated,' although a 3-tiered ceiling was better than a uniform ceiling, which suggests that multi-tiered ceilings 
that are more closely related to households' ability to pay may be preferable if the administrative burdens are not huge, which is true of Korea, where all data on healthcare utilization are electronically managed. Since 2014, a further differentiated (7-tiered) ceiling on copayment has been in place.

Second, the partial effect of the copayment ceiling can be attributed to the high proportion of direct payments for services not covered by the NHI. It was inevitable that the new policy had a partial effect because it focused only on copayments, not on all OOP payments. This implies that extending benefit coverage to the services currently not covered is very important in order to improve financial protection. Considering the rapid introduction of state-of-the-art medical technologies into the Korean healthcare market, policy agendas such as which service items to include in the benefits package of the NHI and how to regulate the utilization of the items not included would be crucial to improving financial protection in the coming years.

This study has some limitations. First, it focused on financial protection as an effect of the differential copayment ceiling, but not on health outcomes. It would be difficult to assess the health effects of this new policy, and a longer time span would be necessary. Further macro-level evaluation studies accounting for health outcomes, transaction costs, and so on are warranted. Second, the KHP data did not provide separate information on copayments and direct payments, and provided only aggregate information on OOP. In order to have a sketchy idea of the composition of OOP payments, the relative weights of the 2 components had to be borrowed from another survey $[14,15]$. Third, regarding the model specification, a variable indicating whether a household has private health insurance was not included. Despite a few studies $[16,17]$ showing no significant insurance effect, there remains the possibility of omitted variable bias, so the estimated coefficients need to be interpreted with caution.

Notwithstanding these limitations, this study made the contribution of examining the effects of the copayment ceiling for the first time in Korea. To summarize, the differential ceiling contributed to increased utilization regardless of income level, and it had limited effects on improving financial protection. This seems to have to do with 2 points: the relatively small number of households benefiting from the differential ceilings and the substantial amount of direct payments for services not covered by the $\mathrm{NHI}$.

\section{ACKNOWLEDGEMENTS}

This work was supported by a National Research Foundation of Korea Grant funded by the Korean government (NRF2013S1A2A1A01066691) and conducted with the support of the Takemi Program in International Health at Harvard School of Public Health. TJ Lee appreciates the valuable comments by Dr. Gunther Fink and Professor Katherine Baicker; however, the authors are solely responsible for the views presented in this paper.

\section{CONFLICT OF INTEREST}

The authors have no conflicts of interest associated with the material presented in this paper.

\section{ORCID}

Tae-Jin Lee https://orcid.org/0000-0003-2539-3579

Chelim Cheong https://orcid.org/0000-0001-5136-6764

\section{REFERENCES}

1. Evans DB, Etienne $C$. Health systems financing and the path to universal coverage. Bull World Health Organ 2010;88(6): 402.

2. Kwon S. Thirty years of national health insurance in South Korea: lessons for achieving universal health care coverage. Health Policy Plan 2009;24(1):63-71.

3. James CD, Hanson K, McPake B, Balabanova D, Gwatkin D, Hopwood I, et al. To retain or remove user fees?: reflections on the current debate in low- and middle-income countries. Appl Health Econ Health Policy 2006;5(3):137-153.

4. Xu K, Evans DB, Carrin G, Aguilar-Rivera AM, Musgrove P, Evans T. Protecting households from catastrophic health spending. Health Aff (Millwood) 2007;26(4):972-983.

5. Galárraga O, Sosa-Rubí SG, Salinas-Rodríguez A, SesmaVázquez $\mathrm{S}$. Health insurance for the poor: impact on catastrophic and out-of-pocket health expenditures in Mexico. Eur J Health Econ 2010;11(5):437-447.

6. Somkotra T, Lagrada LP. Payments for health care and its effect on catastrophe and impoverishment: experience from the transition to Universal Coverage in Thailand. Soc Sci Med 2008;67(12):2027-2035.

7. Spaan E, Mathijssen J, Tromp N, McBain F, ten Have A, Baltus- 
sen R. The impact of health insurance in Africa and Asia: a systematic review. Bull World Health Organ 2012;90(9):685-692.

8. Yardim MS, Cilingiroglu N, Yardim N. Financial protection in health in Turkey: the effects of the Health Transformation Programme. Health Policy Plan 2014;29(2):177-192.

9. Xu K, Evans DB, Kadama P, Nabyonga J, Ogwal PO, Nabukhonzo $P$, et al. Understanding the impact of eliminating user fees: utilization and catastrophic health expenditures in Uganda. Soc Sci Med 2006;62(4):866-876.

10. Meng Q, Xu L, Zhang Y, Qian J, Cai M, Xin Y, et al. Trends in access to health services and financial protection in China between 2003 and 2011: a cross-sectional study. Lancet 2012; 379(9818):805-814.

11. Shahrawat R, Rao KD. Insured yet vulnerable: out-of-pocket payments and India's poor. Health Policy Plan 2012;27(3):213221.

12. Wagstaff A, van Doorslaer E. Catastrophe and impoverish- ment in paying for health care: with applications to Vietnam 1993-1998. Health Econ 2003;12(11):921-934.

13. Jang SM. Development of indicators for assessing anti-hypertensive drugs. Seoul: Health Insurance Review and Assessment Service; 2008, p. 25-26 (Korean).

14. National Health Insurance Service. Survey on patients' out-ofpocket payment in the national health insurance 2009. Seoul: National Health Insurance Service; 2010, p. 56, 114 (Korean).

15. National Health Insurance Service. Survey on patients' out-ofpocket payment in the national health insurance 2011. Seoul: National Health Insurance Service; 2012, p. 31,48 (Korean).

16. Yun HS. Effects of private insurance on medical expenditure. KDI J Econ Policy 2008;30(2): 99-128 (Korean).

17. Kang SW, You CH, Oh EH, Kwon YD. The impact of having private health insurance on healthcare utilization with controlling for endogeneity. Korean J Health Econ Policy 2010;16(1): 139-159 (Korean). 